\title{
ENDOCARDIAL FIBRO-ELASTOSIS IN ADOLESCENTS AND ADULTS
}

\author{
BY \\ F. S. P. VAN BUCHEM, A. ARENDS, AND E. A. SCHRÖDER \\ From the University Hospital, Groningen, Holland \\ Received April 5, 1958
}

Endocardial fibro-elastosis is no rare finding in infants and young children up to two years of age, and as a rule it leads rapidly to death. Panke and Rottino (1955) found that of 129 cases described 78 per cent had died below the age of twelve months. Its frequency is much less in older children and adults (Smith and Furth, 1943; Hughes and Smith, 1953; White and Fennell, 1954; Thomas et al., 1954; Panke and Rottino, 1955; Popper et al., 1956; and Guraieb and Rigdon, 1956). We have observed five older patients with this disease, three of whom showed the typical clinical picture, while the other two showed features only rarely mentioned in earlier publications.

In endocardial fibro-elastosis the endocardium of one or both ventricles and sometimes also of the atrium is greatly thickened. Usually the left ventricle and left atrium are involved. The endocardium has a greyish-white appearance; it is opaque and reminds one of porcelain. The valves may be somewhat thickened, but generally their function is good. The heart is hypertrophic and its weight is twice or thrice the normal. Mural thrombi have often been found on the abnormal endocardium, and they may give rise to emboli. Microscopically, apart from a connective-tissuelike thickening of the endocardium, an increase of the elastic fibres is observed. As a rule there is a sharp demarcation between the thickened endocardium and the underlying myocardium. Sometimes a few fibrotic foci may be found in the subendocardial myocardium. There are no signs of inflammation or fibrinoid necrosis.

\section{Clinical Manifestations}

The signs and symptoms of our patients were very different. As also described in earlier reports, most patients complain of shortwindedness on exertion, but in two of our patients (Cases 2 and 3) bouts of dizziness were of greater importance. Case 2 showed the full Stokes-Adams syndrome, with complete atrioventricular block, in spite of the fact that her age was only 14 . Case 3, an 18year-old girl, had typical angina in addition to the attacks of dizziness. Three of the five patients had palpitation. The fourth had no complaints at all, although the heart considerably increased in size in the course of six years with ultimately sudden death. All patients had enlarged hearts which we have seen increase in size in the course of the observation period ( $1 \frac{1}{2}$ years, $2 \frac{1}{2}$ years, 7 years, and 1 year) in four of them. In Cases 2 and 3 mainly the right ventricle was enlarged, in Case 4 the left ventricle, and in Case 5 both the left and right ventricles. The heart had a globular shape (Fig. 1). In Cases 1, 2, and 5 a systolic murmur was audible at the apex of the heart and at the level of the third intercostal space on the sternum. A gallop rhythm was heard in two patients (Case 2 and 3). The cardiogram also showed greater variations (Table I), three patients having conduction disturbances (Case 2 complete atrioventricular block with right bundle-branch block (Fig. 3), Case 4 prolonged atrioventricular interval $(0.24 \mathrm{sec}$.) with left bundle-branch block, and Case 5, left bundle-branch block). Radiologically, Case 3 showed extensive intracardiac calcification (Fig. 2). This calcification has also been found in infants (Jacobs, 1932; Clement et al., 1952). The blood showed in all cases a normal hæmoglobin content, normal numbers of erythrocytes and 
FIG. 1.-Case 1. Enlarged globular heart, showing enlargement particularly of left ventricle. Congenital malformations of the first and second left ribs.

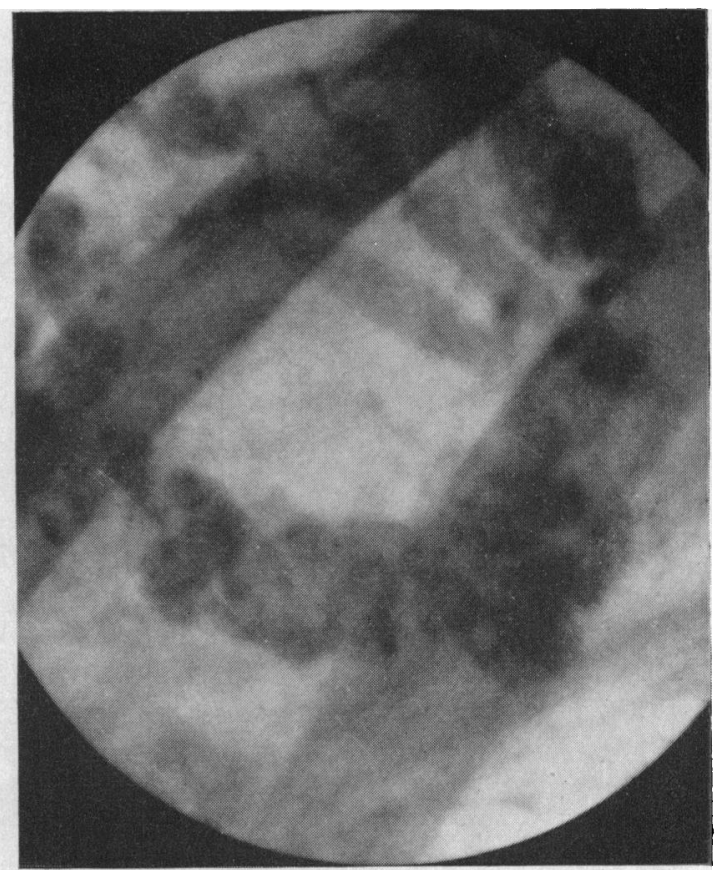

FIG. 2.-Case 3. Calcification in the heart.

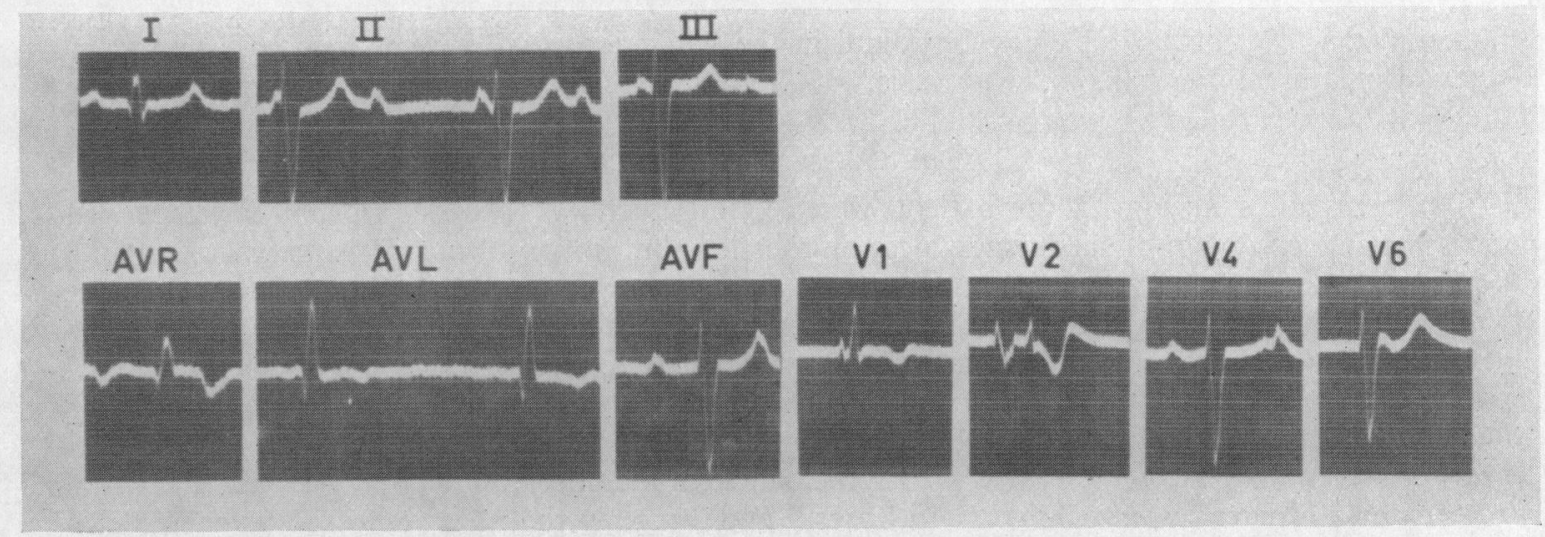

FIG. 3.-Case 2. Complete atrioventricular block with right bundle-branch block.

leucocytes, and normal distribution of the leucocytes, with no eosinophilia (Table I). The E.S.R. was normal. Reactions for syphilis were negative. In one case the complement-fixation test for toxoplasmosis was applied and appeared negative; the Sabin test was 1:96.

Table II gives the results of cardiac catheterization in three patients. In Cases 1 and 5 this examination was carried out when they already had signs and symptoms of congestive heart failure, so that the pressures in superior vena cava and right atrium were increased, as was also the diastolic 
pressure in the right ventricle in Case 1. A high systolic pressure in the right ventricle and pulmonary artery as far as the periphery suggested left congestive heart failure. In Case 4 the examination was carried out when the patient was still free of complaints; only the systolic pressure in right ventricle and pulmonary artery and also in the periphery of the latter artery was somewhat raised, which already pointed to incipient left congestive heart failure. Among previous reports we found

TABLE I

Clinical and Pathological Data of Five Patients with Endocardial Fibro-elastosis

\begin{tabular}{|c|c|c|c|c|c|c|c|c|c|c|}
\hline & $\begin{array}{c}\text { Age } \\
\text { (years) }\end{array}$ & $\begin{array}{c}\text { Blood- } \\
\text { pressure }\end{array}$ & $\mathrm{Hb}$. & $\begin{array}{l}\text { Red cells } \\
\text { (millions } \\
\text { cu. mm.) }\end{array}$ & $\begin{array}{l}\text { W.B.C. } \\
\text { (per cu. } \\
\text { mm.) }\end{array}$ & $\begin{array}{l}\text { Eosino- } \\
\text { phils }\end{array}$ & E.C. & $\begin{array}{l}\text { Heart- } \\
\text { weight }\end{array}$ & $\begin{array}{l}\text { Endocardial } \\
\text { fibro-elastosis }\end{array}$ & $\begin{array}{l}\text { Myoc. } \\
\text { hyper- } \\
\text { trophy }\end{array}$ \\
\hline $\begin{array}{ll}\text { Case } 1 & \ldots \\
\text { Case } 2 & . .\end{array}$ & $\begin{array}{l}13 \\
16\end{array}$ & $\begin{array}{l}115 / 95 \\
110 / 70\end{array}$ & $\begin{array}{r}14 \mathrm{~g} \\
85 \%\end{array}$ & $\begin{array}{l}4 \cdot 7 \\
4 \cdot 7\end{array}$ & $\begin{array}{l}5400 \\
9300\end{array}$ & $2 \%$ & $\begin{array}{l}\text { L.V. strain } \\
\text { A-V block } \\
\text { R.B.B.B. }\end{array}$ & $\begin{array}{l}450 \mathrm{~g} . \\
350 \mathrm{~g} .\end{array}$ & $\begin{array}{l}\text { L.V. } \\
\text { L.V. }\end{array}$ & $\begin{array}{l}\text { L.V. } \\
\text { L.V. }\end{array}$ \\
\hline Case 3 & 18 & $135 / 90$ & $100 \%$ & $5 \cdot 3$ & 7400 & $2 \%$ & $\begin{array}{l}\text { R. vent. } \\
\text { hypert. }\end{array}$ & - & $\begin{array}{l}\text { L.A., L.V. } \\
\text { calcif. }\end{array}$ & R.V. \\
\hline Case 4 & 26 & $135 / 85$ & $100 \%$ & $4 \cdot 3$ & 7000 & $0 \%$ & $\begin{array}{l}\text { L.B.B.B. } \\
\text { P-R } 0 \cdot 24 \\
\text { sec. }\end{array}$ & $920 \mathrm{~g}$. & $\begin{array}{l}\text { L.V., L.A., } \\
\text { R.A. }\end{array}$ & $\begin{array}{l}\text { R. and } \\
\text { L.V. }\end{array}$ \\
\hline Case 5 & 46 & $120 / 90$ & $14.9 \mathrm{~g}$ & $4 \cdot 4$ & 7400 & $2 \%$ & L.B.B.B. & $800 \mathrm{~g}$. & $\begin{array}{l}\text { L.V., R.V., } \\
\text { L.A. }\end{array}$ & $\begin{array}{l}\text { R. and } \\
\text { L.V. }\end{array}$ \\
\hline
\end{tabular}

a similar investigation by catheterization only in the paper of Clark et al., (1956) who also noticed a high diastolic pressure in the right ventricle (Table II), while Adams and Katz (1952) catheterized four patients below the age of 2 years, finding an increased systolic pressure in the right ventricle and pulmonary artery in two of them. In Case 4 the pattern of the right ventricular pressure curve suggests constrictive pericarditis. The ratio end-diastolic pressure: systolic pressure was somewhat higher than $\frac{1}{3}$; Clark found an even higher value. This is of importance, because this pattern is therefore not pathognomonic of constrictive pericarditis, as thought by $\mathrm{Yu}$ et al. (1953).

We were able to make an angiogram in one patient. The right ventricle was small and filled well, as did the pulmonary artery also. The left ventricle was greatly dilated and emptied slowly, so that no filling of the aorta could be seen after 10 seconds.' In this patient the endocardial fibrosis was localized in the left ventricle. The same was found by Prec and Cassels (1952) in an infant.

TABLE II

Results of Cardiac Catheterization in Three Patients with Endocardial Fibro-elastosis

\begin{tabular}{|c|c|c|c|c|c|c|c|c|c|c|c|c|c|}
\hline \multirow[t]{3}{*}{ Case } & \multirow[t]{3}{*}{ Age } & \multirow{2}{*}{\multicolumn{2}{|c|}{$\begin{array}{c}\text { Superior vena } \\
\text { cava }\end{array}$}} & \multirow{2}{*}{\multicolumn{2}{|c|}{ R. atrium }} & \multirow{2}{*}{\multicolumn{2}{|c|}{ R. ventricle }} & \multicolumn{4}{|c|}{ Pulmonary artery } & \multirow{2}{*}{\multicolumn{2}{|c|}{ Radial artery }} \\
\hline & & & & & & & & \multicolumn{2}{|c|}{ Trunk } & \multicolumn{2}{|c|}{ Periphery } & & \\
\hline & & $\mathrm{O}_{2}$ sat. & Press. & $\mathrm{O}_{2}$ sat. & $\begin{array}{l}\text { Press. } \\
\mathrm{mm} . \mathrm{Hg} .\end{array}$ & $\mathrm{O}_{2}$ sat. & Press. & $\mathrm{O}_{2}$ sat. & 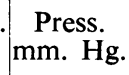 & $\mathrm{O}_{2}$ sat. & Press. & $\mathrm{O}_{2}$ sat. & $\begin{array}{c}\text { Press. } \\
\mathrm{mm} . \mathbf{H g} .\end{array}$ \\
\hline 1 & $13 \mathrm{y}$. & $47 \%$ & 12 & $46 \%$ & 12 & $45 \%$ & $50 / 12$ & $44 \%$ & $50 / 35$ & $96 \%$ & $40 / 25$ & $94 \%$ & $115 / 95$ \\
\hline 4 & $26 \mathrm{y}$. & $63 \cdot 5 \%$ & 4 & $64.5 \%$ & 4 & $64 \%$ & $32 / 0$ & $61 \cdot 5 \%$ & $32 / 15$ & $96.5 \%$ & $13 / 18$ & - & $135 / 85$ \\
\hline 5 & $46 \mathrm{y}$. & $53.5 \%$ & 8 & $41 \%$ & 8 & $42 \%$ & $55 / 0$ & $40 \%$ & $50 / 25$ & $97 \cdot 5 \%$ & 35 & - & $120 / 90$ \\
\hline Clark & $35 \mathrm{y}$. & - & - & - & 32 & - & $39 / 27$ & - & $35 / 30$ & - & 25 & - & - \\
\hline
\end{tabular}

\section{Course of THE Disease}

Older patients, like infants, often die from congestive heart failure (Cases 3 and 5). The course in Case 1 corresponds with that sometimes observed in infants (Dimond et al., 1955), for the condition was complicated by violent diarrhœa and vomiting and she soon got into a state of 
shock from which she did not recover. Our Case 2 died from a complete atrioventricular block, eight days after an infection which had reacted well to antibiotic treatment. According to previous observers, the course in our Case 4 was very uncommon; he died suddenly at the age of 26 without ever having had complaints before, although he had a left bundle-branch block and a progressive dilatation of the heart during his last six years of life (Fig. 7).

Sometimes emboli in the systemic circulation may dominate the clinical picture (Popper et al., 1956). These emboli originate from intracardiac mural thrombi.

\section{PATHOLOGY}

The five cases described all showed more or less a connective-tissue-like thickening of the endocardium (Fig. 4). This abnormality is described as endocardial sclerosis or also, in view of the increase of the elastin which is usually found, under the name of endocardial fibro-elastosis. The cases described in this paper also showed this increase of elastin (Fig. 5 and 6); a striking feature was the granular degeneration of the elastin. The sclerosis of the endocardium is usually evenly diffuse. The process is generally localized in the left ventricle, but may be found as well in the other cavities of the heart. Our cases all showed abnormalities of the endocardium of the left ventricle. In Cases 1 and 2 the abnormalities were confined to the left ventricle, while in Cases 3 and 4 the left atrium and the two atria, respectively, were likewise involved in the process; in Case 5, the left ventricle, left atrium, and right ventricle (Table I). Mural thrombosis was demonstrated in one patient. A striking feature is that there are no inflammatory infiltrations, by which the affection can be distinguished from the fibroplastic parietal endocarditis as described by Löffler. In no cases were there indications of myocarditis or myocardial anoxia. Extension of the process to the valves was not found.

Case 2 showed abnormalities in form and arrangement of the papillary muscles; although the chordae tendineæ were somewhat heavy and short (Fig. 4), the impression was gained that this was a case of congenital defect. Such defects were also found in Case 1 in the form of absence of the left second rib and the presence of a rudimentary first rib. Case 3 had extensive calcium deposits in the thickened endocardium.

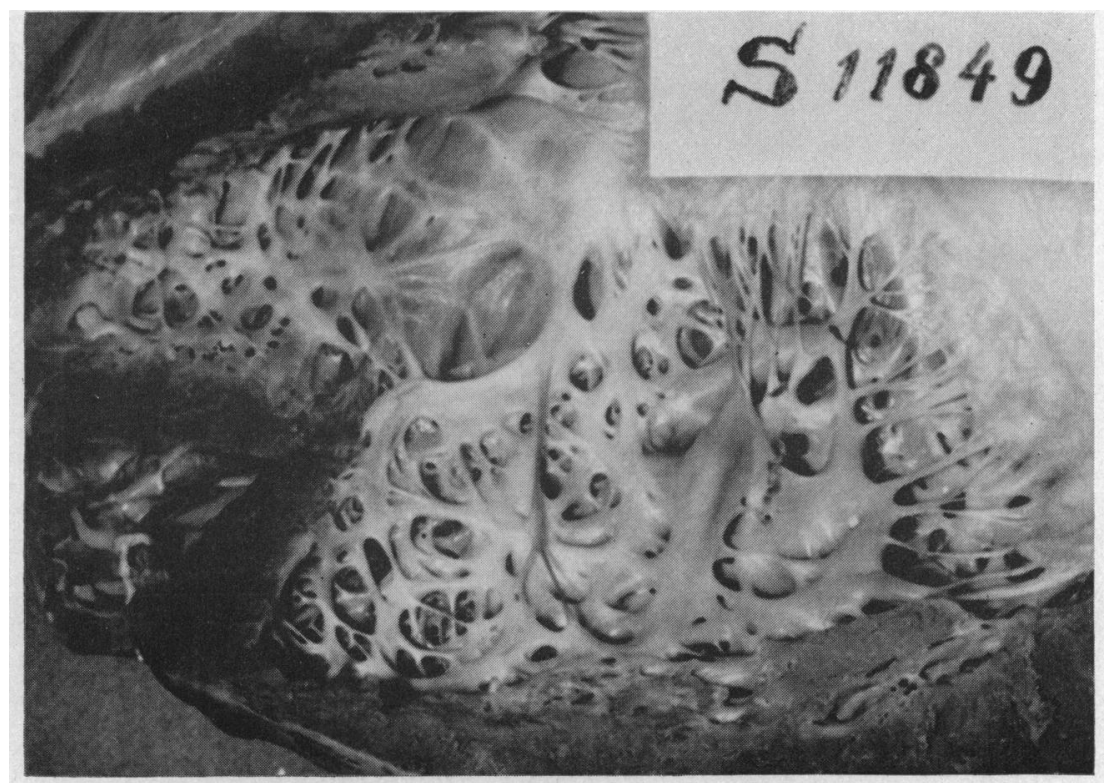

FIG. 4.-Case 2. Left ventricle, showing white thickened endocardium and irregular arrangement and abnormal form of the papillary muscles. 


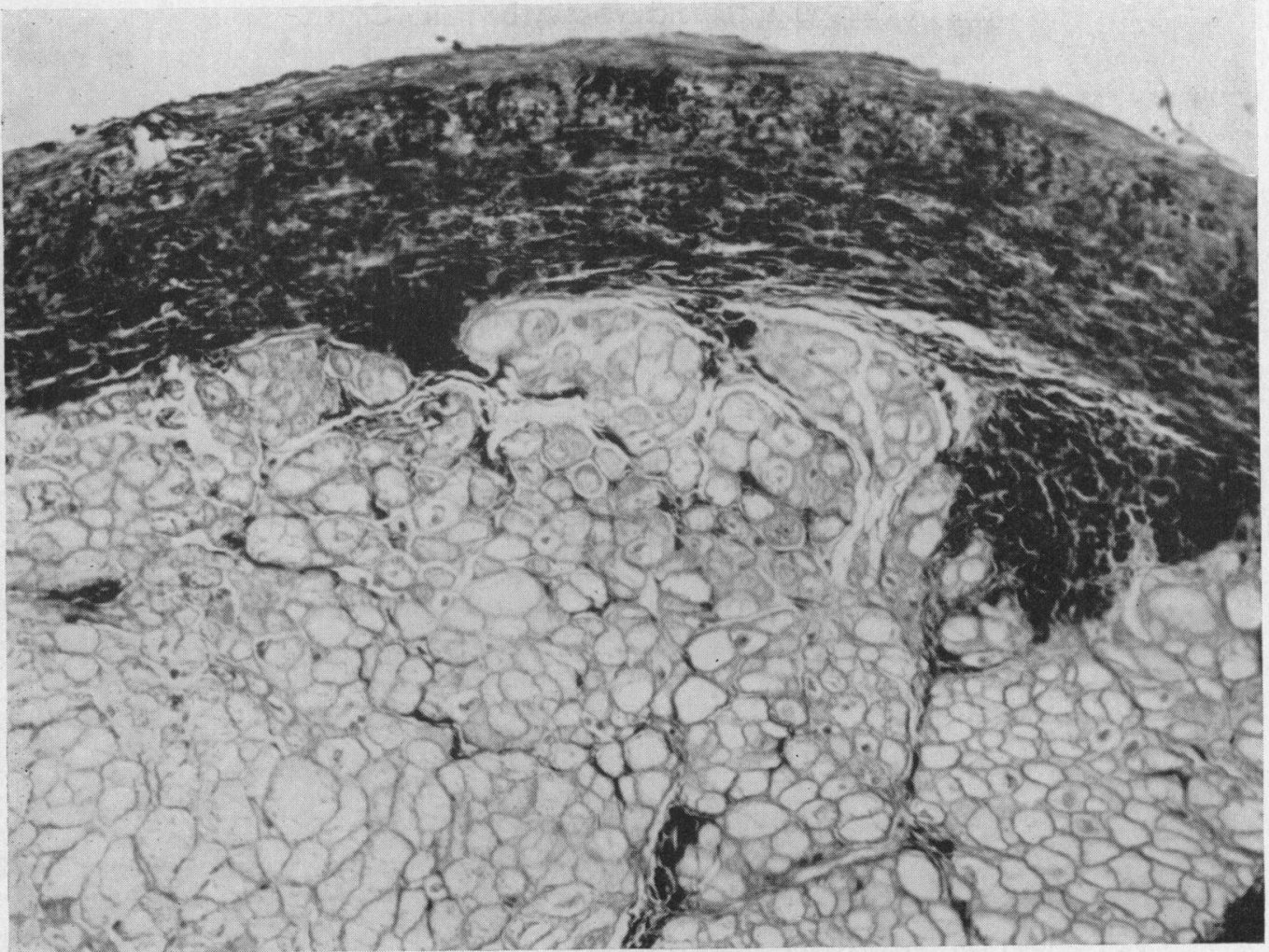

FIG. 5.-Case 1. Microphotograph, showing excessive thickening of the endocardium of the left ventricle with increased and crumbling elastin (v. Gieson-elastin; $\times 160)$.

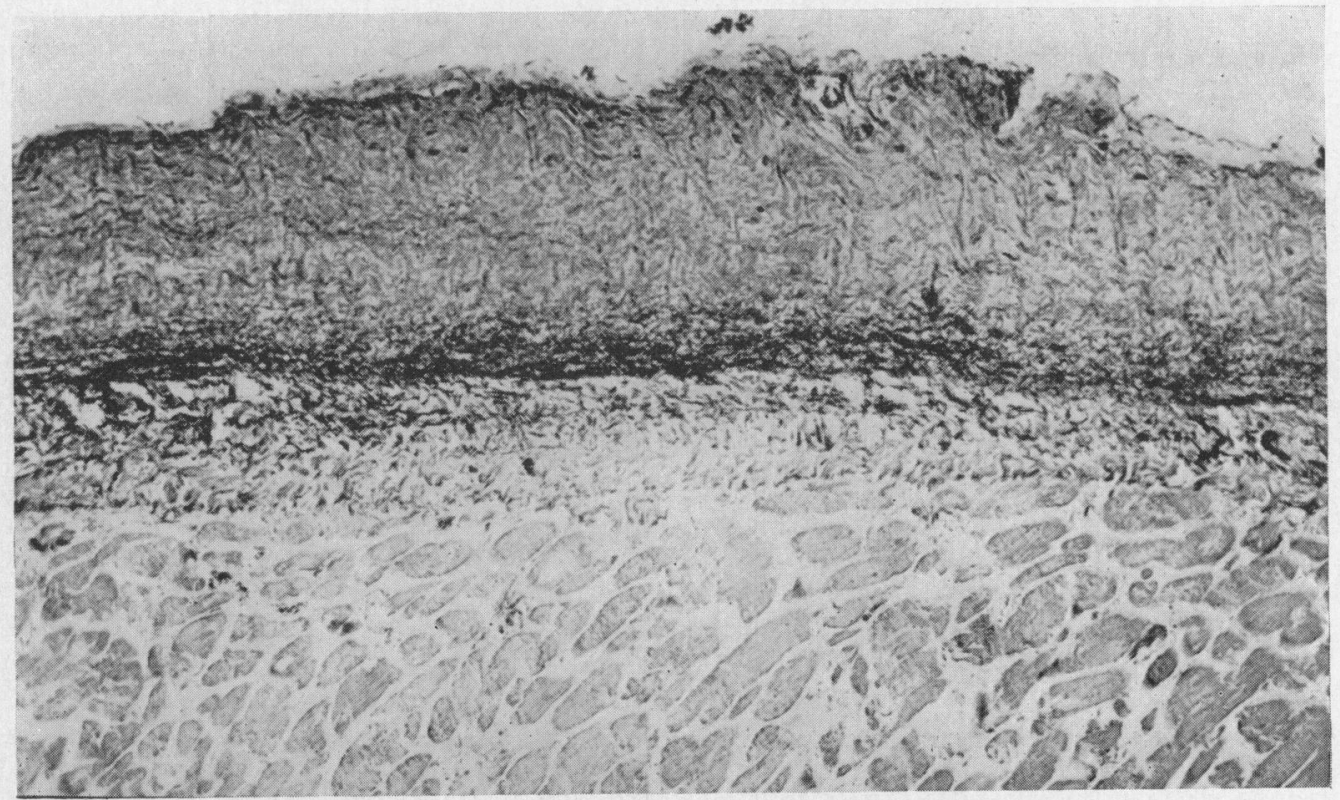

FIG. 6.-Case 4. Microphotograph, showing conspicuous thickening of the endocardium of the left ventricle with increase of elastin (Verhoeff; $\times 100$ ). 
The hypertrophy usually observed in these cases may be mild (Case 2) or very advanced (Case 4). In all patients dilated cardiac cavities were found with congestion both in the pulmonary and systemic circulations.

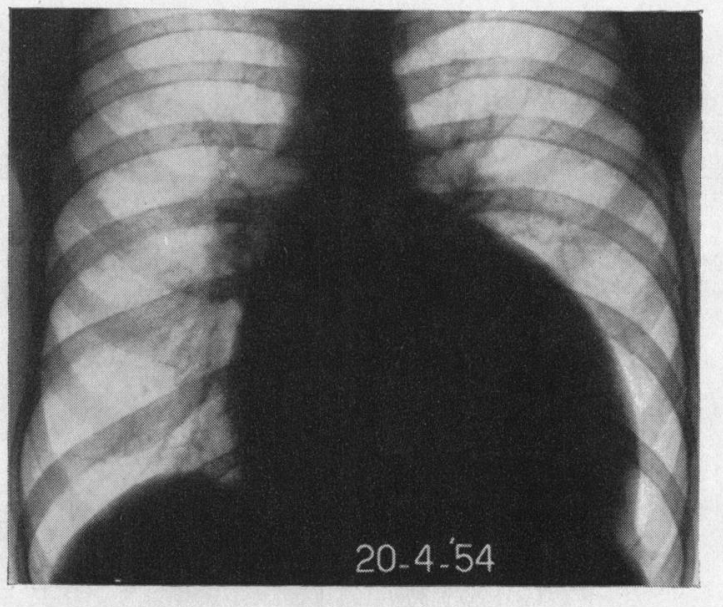

Fig. 7.-Case 4. X-ray of heart six years after onset of illness.

\section{Pathological Physiology}

Endocardial fibro-elastosis may give rise to a greater or lesser decrease in size of the ventricular cavity, accentuated by mural thrombi. Where there is much decrease in size the ventricular cavity has a smaller capacity and diastole is impeded. When the process is localized in both ventricles, the picture may suggest constrictive pericarditis, the more so because there are only small pulsations of the cardiac border; this is the reason why on several occasions thoracotomy has been carried out in these patients (McKusick and Cochran, 1952; Clark et al., 1956). When only one of the ventricles is involved it is usually the left. In this event pulmonary congestion will develop with much hypertrophic dilatation of the right ventricle and right atrium (Cases 2 and 3). On the other hand, the ventricle with the subendocardial fibro-elastosis may prove to be much dilated (as in our Case 4). Then there is apparently only an impeded systole, so that, in spite of the hypertrophy of the myocardium, the emptying is insufficient. Finally, when the left ventricle is involved, pulmonary congestion will arise. This endocardial process sometimes affects the conducting system, so that Adams-Stokes attacks may occur (Case 2).

The murmurs sometimes heard may be based on co-existing congenital valvular defects (Popper et al., 1956: tricuspid stenosis) or more often on relative insufficiency as a result of the dilatation of the ventricle (Cases 1 and 5).

The fact that congestive heart failure may develop, without severe morphological abnormalities of the myocardium being found may in the first place be explained from this unfavourable influence on the ventricular diastole, or systole. Gross (1941) seeks the cause in a disturbed myocardial circulation, due to the constriction or obliteration of the termination of the Thebesian and other vessels caused by the endocardial fibrosis. Thomas et al. (1954) were able to find a continuation of the fibro-elastic thickening on the sinusoids, but no occlusion by thrombosis. This process may promote the development of myocardial insufficiency.

\section{ÆTiology ANd Pathogenesis}

Little is known with certainty of the cause of endocardial fibro-elastosis. The morphological changes found in infants and young children show a great resemblance to those seen in older patients.

In young children the clinical picture also is much like that in older children; in particular there is an 
enlarged globular heart, sometimes with gallop rhythm or murmurs. Prolongation of the P-R or QRS interval has several times been observed. Infants usually show the electrocardiographic picture of left ventricular hypertrophy. In these young patients, however, the disease usually very soon takes a serious turn, with increased venous pressure, hepatomegaly and pulmonary congestion, while the older patients in general have complaints for several years before death ensues.

At present most authors (Weinberg and Himelfarb, 1943; Dimond et al., 1955; Gowing, 1953; and Clement et al., 1952) are inclined to regard endocardial fibro-elastosis in young children as a congenital defect, the more so because it not infrequently occurs in several members of the same family (Nadas, 1957) while other congenital abnormalities (aortic coarctation, patent ductus arteriosus) have been found (Gross, 1941 ; Edmonds and Seelye, 1951). Weinberg and Himelfarb (1943) found the abnormality in two children from one family; one of them had also coarctation of the aorta. In view of the resemblance between the clinical and pathological abnormalities in young children and in older patients, some investigators (Thomas et al., 1954; Guraieb and Rigdon, 1956) are inclined to believe in a congenital pathogenesis also in older patients. Against this is the latent period between birth and the onset of the manifestations. In this connection the observations in four of our patients seem to be of importance. In the first place, the age group in which the abnormalities were found for the first time $(12,14,14$, and 19 years, respectively) form a transition between the youthful and older patients described in previous reports. Moreover, the absence of signs and symptoms in the preceding years does not exclude the pre-existing abnormalities. This is well illustrated by Case 4, in which cardiac enlargement and left bundle-branch block were found at a physical examination at the age of 19 years. The following six years he was absolutely free from symptoms, in spite of a progressive dilatation of the heart. The appearance of the manifestations later in life may be due to a slower progression of the abnormality. Moreover, we found other congenital abnormalities in two of our patients. The low frequency may be explained from the fact that as a rule in youth the affection is already so severe that the majority of patients die early of it. Anoxia of the endocardium is generally accepted as the direct cause of the fibro-elastosis. Endocardial fibrosis occurs regularly in patients in whom a coronary artery originates from the pulmonary artery (Johnson, 1952). In patients with serious coronary sclerosis and infarcts local areas with endocardial fibrosis are a common finding (Weinberg and Himelfarb, 1943; Thomas, 1954). Johnson (1952) supposed that, in utero, an endocardial anoxia would have developed, as a result of early closure of the foramen ovale or insufficient development of the foramen secundum, so that, during the fotal period, no oxygenated blood reached the left atrium and ventricle. Thomas et al. (1954), found in all their cases a closed foramen ovale. This was also the case in our patients but, taking their age into consideration, this does not mean very much. The earlier view that fotal endocarditis might be the cause has been abandoned because evidence of a cured or active inflammation has never been found (Gross, 1941; Thomas et al., 1954).

The mural thrombi, remnants of which are often found on the endocardium, are usually considered to have originated secondarily. Still and Boult (1956) observed by the electron-microscope that the fibres most often found in endocardial fibro-elastosis were not to be distinguished from fibrin. This might suggest that the endocardial thickening is caused by deposition of fibrin from the blood.

Smith and Furth (1943) and Brinkman (1952) believed that this affection was associated with deficient nutrition and they considered the possibility of a vitamin $B_{1}$ depletion. Gray (1951), however, pointed to the fact that the clinical picture of vitamin $B_{1}$ deficiency, i.e., beri-beri, is quite different. Moreover, in this case abnormalities of the myocardium of both ventricles are especially found (Higginson et al., 1952), and no endocardial fibrosis (Davies and Ball, 1955). In addition, it appeared that in most patients (Thomas et al., 1954; annotation Lancet, 1952) just as in our personal cases, there is no question of deficient nutrition, and no favourable results were observed after vitamin $B_{1}$ therapy (Thomas, 1954; Davies, 1955).

\section{DifFERENTIAL DiagnOSIS}

In the first place endocardial fibro-elastosis should be differentiated from the so-called endomyocardial necrosis, as indicated by Thomas et al. (1954) and other writers. The clinical picture of the latter affection shows a great resemblance to the former, notably by the occurrence of congestive heart failure without demonstrable cause. The pathological picture is quite different, however: it is true that in these cases foci of endocardial thickening are found, but in addition to this the endocardium and myocardium are destroyed and replaced by vascular fibrous tissue. Only fragments of the elastic tissue are to be found, in contrast to the increase of the elastic fibres in endocardial fibro-elastosis (Thomas et al., 1954), by virtue of which the name of endomyocardial necrosis or fibrosis is given to this condition (Davies and Ball, 1955). Inflammatory manifestations have also often been found. Lesions of the tricuspid or mitral valves may be present as well, with manifestations of tricuspid or mitral insufficiency. The degenerative abnormalities in the myocardium, leading to fibrosis, are the reason why this clinical picture is named myocarditis fibrosa. The hypertrophy 
is usually far less marked and may even be absent as in the patients described by Becker et al. (1953). This endomyocardial fibrosis has been found in various clinical pictures.

(i) In the endocarditis parietalis fibroplastica with eosinophilia described by Löffler (1936). The eosinophilia is sometimes only present in certain phases of the disease. The presence of endarteritis and periarteritis is regarded as characteristic for this affection (Weiss-Carmine, 1957; Gerbaux et al., 1956; and van den Brekel, 1956).

(ii) In the patients with manifestations of congestive heart failure observed in Africa by Bedford and Konstam (1946) Davies and Ball (1955), and Becker et al. (1953). Here also eosinophilia has sometimes been found, but this was probably associated with concurrent parasitic diseases. In these cases the manifestations of more general endarteritis and panarteritis are lacking (WeissCarmine, 1957). Davies and Ball in several instances found calcium deposits in the endocardium. The cases with only local endocardial fibrosis, as may be observed in myocardial infarctions, do not of course belong to the clinical group of idiopathic endocardial fibro-elastosis.

The diagnosis of endocardial fibro-elastosis should therefore be considered in patients of all ages when progressive cardiac dilatation develops without clear cause, whether or not it is combined with congestive heart failure. Indications suggesting this disease are slight excursions of the cardiac border on radioscopy, conduction disturbances especially at a youthful age, and possibly emboli in the systemic circulation. Pulmonary congestion is the first manifestation to be expected, as the left ventricle is usually involved. In the beginning the pressure values in the right heart may be normal, but, owing to the pulmonary congestion, the pulmonary arteriolar resistance rises, as also the systolic pressure in the right ventricle and pulmonary artery. The configuration of the ventricular pressure curve may be the same as that in constrictive pericarditis (Case 4). Moreover, endocardial fibro-elastosis should be considered if extensive congestion with high venous pressure, large liver, ascites, and œdema develop while the heart is only little enlarged, so that valvular defects, hypertension, and myocardial infarction are ruled out. In these cases one should also think of constrictive pericarditis, amyloidosis of the heart, and endocardial fibrosis. In the differential diagnosis from constrictive pericarditis, a past history, earlier exudative pericarditis, and the presence of calcium deposits in the pericardium may be indications for the last named disease. Atrioventricular or bundle-branch block, if present, are arguments in favour of endocardial fibrosis. The diagnosis of amyloidosis of the heart can be established by means of biopsy of the liver which will also contain amyloid.

Treatment can only be symptomatic; it may be needed for congestive heart failure and arrhythmias. Should emboli occur anticoagulant treatment must be considered, although Hughes and Smith (1953) did not secure any good results from such treatment in their patients.

\section{SUMMARY}

The clinical and pathological findings in five patients suffering from endocardial fibro-elastosis are reported. Their ages were 13,16, 18, 26, and 46 years. Some were observed for several years.

A survey is given of the clinical picture, which may show great variations. Usually progressive dilatation of the heart and the manifestations of congestive heart failure are the predominant features. One woman died from Adams-Stokes syndrome and a second died suddenly without ever having had any complaints.

All five patients showed the characteristic abnormalities of the endocardium (thickening of connective tissue with increase of the elastin), intact valves, and as the sole abnormality of the myocardium, hypertrophy. In each case the anomaly was localized in the endocardium of the left ventricle. One patient had extensive calcification of the endocardium. The hæmodynamic consequences are discussed.

Little is known of the ætiology and pathogenesis. We think the condition is probably a congenital one.

In the differential diagnosis the following conditions are discussed: constrictive pericarditis and 
amyloidosis of the heart, and the various forms of endomyocardial fibrosis as often observed in Africa, and endocarditis parietalis fibroplastica (Löffler); the two last mentioned diseases show quite a different pathological picture.

\section{REFERENCES}

Adams, F. H., and Katz, B. (1952). J. Pediatr., 41, 141.

Annotation (1952). Lancet, 1, 90.

Becker, B. J. P., Chatgidakis, C. B., and van Lingen, B. (1953). Circulation, 7, 345.

Bedford, D. E., and Konstam, G. L. S. (1946). Brit. Heart J., 8, 236.

Brekel, C. H. N. van den (1956). Endocarditis parietalis fibroplastica. Thesis. Amsterdam.

Brinkman, G. L. (1952). New Zealand med. J., p. 173.

Buchem, F. S. P. van (1946). Acta med. Scand., 125, 182.

Clark, G. M., Valentine, E., and Blount, S. G. (1956). New England J. Med., 254, 349.

Clement, R., Gerbeaux, J., and Couvreur, J. (1952). Presse méd., 2, 1767.

Davies, J. N. P., and Ball, J. D. (1955). Brit. Heart J., 17, 337.

Dimond, E. G., Allen, F., and Moriarity, L. R. (1955). Amer. Heart J., 50, 651.

Edmonds, A. W., and Seelye, W. B (1951). Pediatrics, 7, 651.

Gerbaux, A., De Brux, J., Bennacoeur, M., and Lenegre, J. (1956). Bull, Soc. Méd. Hôp. Paris, $72,456$.

Gowing, N. F. C. (1953). J. Path. Bact., 65, 13.

Gray, I. R. (1951). Brit. Heart J., 13, 387.

Gross, P. (1941). Arch. Pathol., 31, 163.

Guraieb, S. R., and Rigdon, R. N. (1956). Amer. Heart J., 52, 138.

Higginson, J., Gillander, A. D., and Murray, J. F. (1952). Brit. Heart J., 14, 213.

Hughes, A., and Smith, G. H. (1953). Brit. Heart J., 15, 450.

Jacobs, W. F. (1932). Arch. Path., 14, 129.

Johnson, F. R. (1952). Arch. Path., 54, 237.

Löffler, W. (1936). Schweiz. med. Wochenschr., 66, 817.

McKusick, V. A., and Cochran, T. H. (1952). Bull. Johns Hopkins Hosp., 90, 90.

Nadas, A. (1957). Pediatric Cardiology. W. B. Saunders, Philadelphia \& London.

Panke, W., and Rottino, A. (1955). Amer. Heart J., 49, 89.

Popper, H., Kushner, D. S., and Gasul, B. (1956). Circulation, 14, 412.

Prec, K. J., and Cassels, D. E. (1952). J. Pediatr., 41, 451.

Smith, J. J., and Furth, J. (1943). Arch. intern. Med., 71, 602.

Still, W. J. S., and Boult, E. N. (1956). Lancet, 2, 117.

Thomas, W. A., Randall, R. V., Bland, E. F., and Castleman, B. (1954). New England J. Med., $251,327$.

Yu, T. N. G., Lovejoy, F. W., Joos, H. A., Nye, R. E., and Mahoney, E. B. (1953). Circulation, 7, 102.

Weinberg, T., and Himelfarb, A. J. (1943). Bull. Johns. Hopkins Hosp., 72, 299.

Weiss-Carmine, S. (1957). Schweiz. med. Wochenschr., 87, 890.

White, P. D., and Fennell, R. H. (1954). Ann. intern. Med., 41, 333. 